\title{
LAS ARRAS PERFECCIONADAS A TRAVÉS DE UN CHEQUE
}

\author{
MAKING EARNEST PAYMENTS WITH A CHECK \\ SENTENCIA DE LA CORTE SUPREMA DE 6 DE MAYO DE 2008 \\ $\left(\text { ROL N }{ }^{\circ} 632-2007\right)^{1}$ \\ PATricio-Ignacio CarvajaL ${ }^{*}$
}

\begin{abstract}
RESUMEN: Se critica el presente fallo, pues resulta perfectamente posible constituir arras a través de un cheque. Dicho documento no es dado en garantía, sino para constituir una garantía; lo cual es muy distinto. Como las arras requieren, para su perfeccionamiento, que se dé, se debe concluir que el cheque en virtud del cual se constituyen fue otorgado en pago, y por tanto es un medio absolutamente válido para tal efecto. Además, las arras son una institución distinta de la cláusula penal; por lo que no se puede aplicar, a la sanción de las arras, las disposiciones sobre cláusula penal enorme.
\end{abstract}

Palabras clave: Arras; compraventa; cheque; cláusula penal; garantía.

ABSTRACT: This article criticizes the referenced decision on the grounds that it is perfectly permissible to make an earnest payment by check. It is not given as a guarantee but constitutes one, which is different. As an earnest payment requires delivery to be legally effective, one may logically conclude that this type of commercial paper is given as a payment, rendering the check absolutely valid for this purpose. In addition, the down payment is a separate matter from the application of the penalty clause. For that reason, it is impermissible to sanction an earnest payment via the legal provisions of the penalty clause.

Key words: Earnest payment, contract of sale and purchase, check, penalty clause, guarantee.

\section{LOS HECHOS:}

Los hechos fundamentales, acreditados en el fallo contra el que se intentó sin éxito la casación en el fondo -además de en la forma-, son los siguientes (Considerando SEXTO):

1.- Con fecha 17 de agosto de 2000 se celebró una compraventa de un vehículo entre un establecimiento automotriz y un particular.

2.- El vehículo objeto de dicha compraventa se encontraba completamente determinado: vehículo marca Mercedes Benz S 420, patente [XXX]. Y lo mismo debe decirse del precio, que ascendió a \$25.500.0000.

3.- Por otra parte, en la ocasión la parte compradora entregó un cheque por la suma de \$25.968.500.000. En virtud de lo anterior, la parte vendedora extendió un

1 "Rivera con Pérez" (2008).

* Licenciado en Ciencias Jurídicas de la Pontificia Universidad Católica de Chile, Doctor en Derecho, Universidad de Salamanca, España. Correo electrónico: carvajal@uc.cl 
documento titulado "reserva y/o recibo de dinero". En su interior, el documento da cuenta de que la suma se recibió "por la compra del vehículo marca Mercedes Benz S 420, patente [XXX]”. Luego, el documento añade el precio de la venta y la forma de pago, la cual sería un "cheque... que se cambiará por vale vista durante el curso de la próxima semana". Por último, el documento indica la función que estaba llamada a cumplir la entrega de la suma enterada a través del cheque: “...ha sido para reservar el vehículo al [comprador]... hasta que se concrete definitivamente esta compraventa. Esta compraventa compromete a [la parte vendedora] a no ofrecer el vehiculo a otros posibles interesados. En consecuencia... en caso de que el [comprador]... no concretara en definitiva la compra del vehiculo, o desistiera de su intención de hacerlo, la suma ya recibida no será devuelta quedando para la empresa por concepto de indemnización”.

4.- Por último se debe añadir que nunca se realizó la sustitución del cheque por un vale vista.

\section{COMENTARIO.}

Hemos seguido la pista al tema de las arras desde hace ya algunos años ${ }^{2}$. De manera que en este comentario nuestro objetivo es, sencillamente, desarrollar lo ya estudiado contemplando la praxis judicial chilena.

A nuestro juicio, en este caso se perfeccionó una compraventa entre las partes. Y en nada obsta a lo anterior que se haya pactado la entrega de un cheque "hasta que se concrete definitivamente esta compraventa", o que se utilizara también la expresión "no concretara en definitiva la compra del vehiculo, o desistiera de su intención de hacerlo". Las expresiones de las partes no son muy afortunadas, pero nos parece constatar la presencia de consentimiento, precio y cosa. A este respecto, parece bastar que el documento otorgado por las partes señalara que se daba el cheque "por la compra del vehiculo marca Mercedes Benz S 420, patente [XXX]"; y por sobre todo, que se dijera: "Esta compraventa compromete a [la parte vendedora] a no ofrecer el vehiculo a otros posibles interesados". Que el consentimiento sea más bien precario, es propio de todo contrato en el que introducen $\operatorname{arras}^{3}$. Esto es lo que trataré a continuación.

El acuerdo de las partes, tal como señalaba la parte ejecutante al deducir la casación en el fondo, se debe entender como arras. Y, añadimos nosotros, específicamente como "arras penitenciales"'; así llamadas, pues permiten la penitencia o arrepentimiento de las partes.

Precisamente el artículo 1803 señala "Si se vende con arras, esto es, dando una cosa en prenda de la celebración o ejecución del contrato, se entiende que cada uno de los contratantes podrá retractarse; el que ha dado las arras, perdiéndolas; y el que las ha recibido, restituyéndolas dobladas". En el caso en cuestión se dieron arras para garantizar la

\footnotetext{
2 Carvajal (en prensa); CARVajal (2007a) pp. 203-243; CARVAJAL (2006) pp. 529-560; CARVAJAL (2007b) 36 pp.; Carvajal (2005) pp. 299-327; CARVAJAL (2003) pp. 231-264; CarVAJAL (2001) pp. 11-61.

3 CARVAJAl (2003) pp. 262 a 264; CARVAjal (2005) pp. 325 a 327.

${ }^{4}$ Carvajal (2001) p. 16; Carvajal (2006) p. 531.
} 
ejecución del contrato o, en el lenguaje de las partes, para la concreción definitiva del contrato. Con todo, si se estimara -a diferencia de lo que estamos sosteniendo- que las expresiones de las partes deben entenderse como que aún no se ha formado el contrato de compraventa, también habría un pacto arral; aunque ahora para garantizar la celebración del contrato. En este último caso, ya he tenido ocasión de señalar -con el apoyo a mi tesis por parte de la doctrina reciente $-^{5}$ que, para el Derecho Civil, la garantía arral debe ser llamada, y entendida, como "arras obligacionales"6.

Dice, el artículo 1805: "Si expresamente se dieren arras como parte del precio, o como señal de quedar convenidos los contratantes, quedará perfecta la venta; sin perjuicio de lo prevenido en el artículo 1801, inciso 2. ${ }^{\circ}$. I No constando alguna de estas expresiones por escrito, se presumirá de derecho que los contratantes se reservan la facultad de retractarse según los dos artículos precedentes". Las arras indicadas en el inciso primero son las denominadas "arras confirmatorias" se ha perfeccionado; y, por ello, no dan cabida a la retractación por efecto de la regla general del artículo $1545^{\circ}$. Ahora bien, no podría pensarse que en este caso las arras sean de este tipo, y no penitenciales o bien obligacionales. En efecto, el documento acreditado en el juicio se titula "reserva y/o recibo de dinero". Y, a pesar de que también señala que el precio se pagará con el mismo cheque entregado en arras, no por ello se puede tener inmediatamente su entrega como parte del precio. Primero, su entrega no es a título de precio, sino que expresamente "...ha sido para reservar el vehículo al [comprador]... hasta que se concrete definitivamente esta compraventa... En consecuencia... en caso de que el [comprador]... no concretara en definitiva la compra del vehículo, o desistiera de su intención de hacerlo, la suma ya recibida no será devuelta quedando para la empresa por concepto de indemnización". Segundo, nada impide que en pos de una razonable economía de gestiones, la suma dada en arras posteriormente se impute al precio. Y, por último, la presunción del inciso segundo opera para el caso inverso; esto es, para fijar definitivamente la posibilidad de retractación cuando no conste por escrito que las arras se dan como parte del precio, o señal de quedar convenidos los contratantes. Pero, por el contrario, no para cuando esas expresiones puedan aparecer en un documento. En este caso habrá que estar, obviamente, a los términos de lo pactado: si nada más se dijo, entonces hay arras confirmatorias; si se agregó la posibilidad de arrepentimiento -como ocurre en la especie-, entonces hay arras obligacionales o penitenciales?

Se platean varios problemas a la luz de la sentencia analizada.

El primero de ellos surge de la constitución de la garantía arral a través de un cheque. El segundo problema se refiere al monto de las arras, que supera incluso el monto del precio.

En cuanto a la constitución de las arras a través de un cheque, razona la Excelentísima Corte respecto del fallo recurrido de la siguiente manera (considerando SEXTO):

\footnotetext{
${ }^{5}$ Verdera (2005) p. 93 n. 3; Estival (2006) p. 51 n. 94.

${ }^{6}$ Carvajal (2001) pp. 14 y 15; Carvajal (2006) p. 532.

7 Carvajal (2001) pp. 12, 15 y 16; CARVAJAL (2006) pp. 529 y 530.

${ }^{8}$ Carvajal (2003) pp. 243 a 253; Carvajal (2005) pp. 310 a 317.

9 Carvajal (2003) p. 254; Carvajal (2005) p. 318.
} 
"los sentenciadores señalan que la ejecutante absolvió posiciones y reconoció que el cheque iba a ser cambiado por un vale vista, lo que nunca sucedió, desprendiéndose de lo anterior que el cheque fue entregado en garantía, con el objeto de cambiarlo por un vale vista en un plazo determinado, de lo que resulta, a su vez, que el documento no estaba destinado al pago".

Lo afirmado por los sentenciadores no se puede compartir. Los términos del acuerdo están acreditados, y según estos la suma "fue recibida" a través de un cheque. De hecho se otorgó un "recibo de dinero". El hecho de que el vendedor aceptara la posterior sustitución del cheque por un vale vista en nada obsta a lo anterior. Por lo demás, no hay duda acerca de que las partes celebraron un pacto arral. Y las arras constituyen un contrato de garantía que, desde el punto de vista de su perfeccionamiento es de carácter real ${ }^{10}$; pues el precepto dice "dando" una cosa en prenda de la celebración o ejecución del contrato. Así, para que se constituyan las arras pactadas es necesario que se dé; y esto ha sido precisamente, una vez esclarecida la presencia del contrato arral, lo que se debió interpretar como ocurrido en virtud de la intervención del cheque. Una vez "dado" el cheque -o más bien, la suma que representa- es indiferente que el vendedor acepte el reemplazo del documento por un vale vista: garantía, dación y subrogación en el objeto de las arras son cosas absolutamente distintas

Puede presumirse, en todo caso, que la parte recurrente no entendía bien el funcionamiento de la garantía arral. En la primera instancia señaló que el cheque no fue dado en garantía, sino que en pago; en cambio, tanto en la segunda instancia como en la casación señaló, erróneamente, lo contrario: que el cheque sí se dio en garantía. Y de hecho, aquí fundamenta el primero de los errores de derecho en que sostiene su casación. Alega la plena validez de un cheque dado en garantía (considerando QUINTO): “En sintesis, termina el recurso respecto de este primer error de derecho, el hecho que el cheque fuera entregado en garantía no lo priva de eficacia ni, por consiguiente, de mérito ejecutivo, ya que el demandado no cumplió su obligación principal de entregar oportunamente un vale vista por la misma cantidad del cheque".

No hace falta mayor comentario respecto del muy justificado rechazo de la Excelentísima Corte a lo que nos parece a todas luces, respetuosamente, un mal argumento (considerando OCTAVO).

Sin embargo, efectivamente la Excelentísima Corte cometió un error de derecho. Precisamente olvidó que las arras se constituyen "dando". Por lo tanto, es completamente impertinente sostener que el cheque, en ese contexto, se dio en garantía; pues realmente se dio en pago: la única forma posible de perfeccionar las arras.

Esto último se relaciona íntimamente con el segundo error de derecho que alega la parte recurrente.

En orden a este segundo error de derecho (considerando QUINTO): “el recurrente expresa que la figura de que da cuenta el documento invocado en la sentencia corresponde claramente a la venta con arras de que tratan los artículos 1803, 1804 y 1805 del Código Civil. I En el caso de autos, sigue el recurso, se trata especificamente de la situación del

${ }^{10}$ Carvajal (2003) p. 256; Carvajal (2005) p. 320. 
artículo 1803 y, por consiguiente, habiéndose retractado la parte que habia dado las arras, debe perderlas..."

Respecto de esta parte del argumento -que nosotros compartimos- razona la Excelentísima Corte (considerando NOVENO): "la institución a que se refiere el artículo 1803 del Código Civil no puede tener aplicación a un caso como el de la especie. I Según este precepto, si se vende con arras, esto es, dando una cosa en prenda de la celebración o ejecución de un contrato, se entiende que cada uno de los contratantes podrá retractarse; el que ha dado las arras, perdiéndolas; y el que las ha recibido, restituyéndolas dobladas. Como puede advertirse, la ley se sirve de la expresión prenda como sinónimo de garantía, lo cual supone que las partes han de servirse de un instrumento que, por su naturaleza, sea apto para constituir, precisamente, una garantía. I Pues bien, según se dijo en los fundamentos precedentes, en nuestro ordenamiento el cheque, en cuanto tal, no puede revestir tal condición, esto es, servir de garantía, lo que no quiere significar que en una operación como la de autos - la compraventa de un vehiculo- no pueda venderse con arras, sino unicamente que el instrumento de que una de las partes pretendió valerse no era apto para ello, por cuanto ahora se decide sobre el cobro del cheque y no sobre el cumplimiento del contrato.

Discrepamos absolutamente de lo señalado en la presente sentencia cuando dice que "el instrumento de que una de las partes pretendió valerse no era apto para ello". Nada tiene que ver que las arras sean una forma de garantía con la manera en que estas se perfeccionan: vale decir "dando". Por ello, reiteramos, nada influye al respecto que el cheque en garantía no esté permitido, pues el cheque que se utiliza para constituir las arras no tiene tal calidad, sino la de un cheque dado en pago. En esto, es ahora la Excelentísima Corte la que no parece comprender bien el funcionamiento de las arras.

Con todo, el error de derecho alegado apuntaba todavía en otra dirección. El fallo de segunda instancia señalaba (considerando SEXTO) "que la ejecutante absolvió posiciones y reconoció que el cheque iba a ser cambiado por un vale vista, lo que nunca sucedió, desprendiéndose de lo anterior que el cheque fue entregado en garantía, con el objeto de cambiarlo por un vale vista en un plazo determinado, de lo que resulta, a su vez, que el documento no estaba destinado al pago. I En razón de lo anterior, terminan los jueces, resulta inoficioso pronunciarse sobre la nulidad de la obligación, también alegada como excepción por el ejecutado". Por ello, la parte recurrente añade a lo ya señalado sobre arras que (considerando QUINTO) "la ley no contiene ninguna limitación respecto de la relación o proporción entre el monto de las arras y el importe del precio, por lo que incluso por analogía del artículo 1544 del mismo Código no puede considerárselas enormes".

El tribunal de segunda instancia estimó inoficioso pronunciarse sobre la pretendida nulidad de la obligación, pues ya había determinado -erróneamente- que el cheque, en línea de principio, no servía para constituir las arras, puesta estas son una garantía y no se admite el cheque en garantía. Con todo, la parte recurrente tenía razón. Efectivamente, no hay proporcionalidad alguna entre el monto de las arras y el monto del precio. Por lo demás, las arras no constituyen una cláusula penal ${ }^{11}$. Es cierto que ciertas

11 Carvajal (2003) pp. 256 a 259; CARVAJAL (2005) pp. 320 a 322. 
legislaciones comparadas modernas tratan en conjunto la cláusula penal y las arras ${ }^{12}$. Pero precisamente en los textos comparados, donde se trata ambas instituciones en conjunto, no se llega a confundirlas debido a sus profundas diferencias. Solo enumeraré algunas de ellas. Primero, la cláusula penal es convencional; en cambio, las arras son siempre reales. Segundo, las arras son una cláusula accesoria, que no subsiste si se invalida el contrato en el que participa; en cambio las arras no son una cláusula del contrato, sino un contrato diverso: malamente podrían ser una cláusula accesoria de una compraventa - consensual o escrita-, pues esta no contiene en sí misma los atributos para que nazcan las arras -la dación-. Tercero, la cláusula penal, en tanto avaluación de perjuicios, da lugar a una obligación subsidiaria: la de indemnizar ante la falta de cumplimiento íntegro, exacto y oportuno de la obligación principal; en cambio la pena arral es una obligación principal, pues de hecho el contrato desaparece por retractación y, por tanto, la obligación de la pena es la única subsistente. Cuarto, la cláusula penal es una avaluación anticipada del monto de los perjuicios; en cambio, las arras son una pena privada, y de ahí la indiferencia de la relación entre los montos de las arras y del precio -el recibo dado al comprador hablaba erróneamente de que las arras se daban como indemnización-13. Quinto, la cláusula penal releva de la necesidad de probar el monto de los perjuicios por el incumplimiento; en cambio, las arras excluyen la posibilidad de que existan perjuicios indemnizables, pues dan el derecho a retractarse, y quien ejerce su derecho no es responsable -malamente puede haber perjuicio por incumplimiento si la fuente de la obligación, el contrato, desaparece por retractación-. Respecto de esto último, "desistir" e "incumplir" son hipótesis tan distintas entre sí, que incluso se excluyen la una a la otra.

En suma, creemos que con el rechazo de la casación en el fondo efectivamente se vulneró el Derecho, al consentir que el cheque no se cobrara a través de un juicio ejecutivo.

\section{BIBLIOGRAFÍA CITADA.}

CARVAJAL, Patricio-Ignacio (en prensa): Las arras en la jurisprudencia chilena (III Jornadas de Derecho Civil de la Universidad Gabriela Mistral).

CARVAJAL, Patricio-Ignacio (2007a): "Las arras hasta su sistematización en los derechos helenísticos”, en: Estudios de Derecho Romano en Homenaje al Profesor Dr. D. Francisco Samper (con ocasión de su jubilación en la Pontificia Universidad Católica de Chile), P.-I. Carvajal (ed.) (Schola Serviana Iuris Romani, Librotecnia, Santiago) pp. 203-243.

CARVAJAL, Patricio-Ignacio (2006): "Las arras penitenciales en el derecho justinianeo", Revista Chilena de Derecho vol. 33 n³: pp. 529-560.

CARVAJAL, Patricio-Ignacio (2007b): “La incorporación justinianea de las arras penitenciales pacto perfecto data”, Revista General de Derecho Romano n 7: 36 pp.

\footnotetext{
12 Carvajal (2006) p. 529 n. 3.

13 CARVAJAL (2003) pp. 259 a 262; CARVAJAL (2005) pp. 322 a 325.
} 
CARVAJAL, Patricio-Ignacio (2005): "Las arras penitenciales en la tradición romanística del derecho civil español", Revista Chilena de Derecho vol. 32 n² 2: pp. 299-327.

Carvajal, Patricio-Ignacio (2003): "Las arras penitenciales", en: El Dret Civil Català en el Context Europeu, coordinador: Àrea de Dret Civil (Universitat de Girona, Documenta Universitaria, Girona) pp. 231-264.

CARVAJAL, Patricio-Ignacio (2001): "El polimorfismo de las arras contractuales en el derecho civil moderno", Revista Jurídica Internacional de la Universidad Veracruzana, Academia, vol. 2, pp. 11-61.

EsTival, Luis (2006): El contrato de arras (Difusión Jurídica y temas de Actualidad, Madrid) $234 \mathrm{pp}$.

VERDERA, Beatriz (2005): Los elementos definitorios de las arras en el derecho patrimonial (Fundación Beneficentia et Peritia Iuris. Colegio de Registradores de la Propiedad y Mercantiles de España, Madrid) 252 pp.

\section{DISPOSICIONES CITADAS}

\section{Código Civil}

art. 1544

art. 1545

art. 1803

art. 1805

Decreto con Fuerza de Ley $\mathrm{N}^{\circ} 707$, Ley sobre cuentas corrientes bancarias y cheques, Publicado en el Diario Oficial de 7 de octubre de 1982.

art. 10

art. 11

Ley $\mathrm{N}^{\circ} 18092$, Dicta nuevas normas sobre letra de cambio y pagare y deroga disposiciones del Código de Comercio, Publicada en el Diario Oficial de 14 de enero de 1982. art. 11

art. 12

\section{JURISPRUDENCIA CITADA}

Álvaro Rivera Durán con Fernando Pérez García (2008): Corte Suprema: 6 de mayo de 2008 (Casación en la forma y en el fondo) causa, Rol 632-2007, Disponible en Legal Publishing On line $\mathrm{N}^{\circ} 38876$. 
